\title{
ESTUDO DO MERCADO DE BOLBOS DE NARCISOS: APROXIMAÇÃO AO MERCADO NACIONAL*
}

Paulo Castro Ribeiro**

\begin{abstract}
Com base nas recomendações da convenção de Berna, foram inventariadas as espécies selvagens ameaçadas ou em vias de extinção, devido ao comércio desregulado das mesmas. A Serra da Estrela foi, até 1992, alvo de pilhagem mais ou menos indiscriminada do seu património florestal, no qual se incluem bolbos de narcisos de três espécies protegidas.

O Projecto de Valorização da Flora Espontânea da Serra da Estrela pretende salvaguardar a diversidade florestal, através de uma iniciativa de desenvolvimento regional que possibilite ds populaçôes de altitude obterem um acréscimo de rendimento pela sua participação activa na salvaguarda da referida flora, em substituição da tradicional "pilhagem" da mesma. Para tal torna-se necessário tomar conhecimento das características $e$ mecanismos de mercado, onde a comercialização controlada destes bolbos possa ser levada a efeito.
\end{abstract}

\section{INTRODUÇÃO}

No âmbito de um projecto de Valorização da Flora Espontânea da Serra da Estrela, que envolveu, entre outras entidades, o Parque Natural da Serra da Estrela, o Instituto de Conservação da Natureza e o Ministério do Ambiente e Recursos Naturais, foi realizado um estudo, tendo por objectivo central aumentar o nível de conhecimento sobre os processos de comercialização (mercado, canais, embalagem, etc.) de bolbos de narcisos. Porquê bolbos de narcisos? De acordo com documentação produzida pelo Ministério do

**Assistente, Universidade Católica Portuguesa - IUDPS (Viseu). 
Ambiente e dos Recursos Naturais, em Portugal, as espécies de plantas bolbosas colhidas na natureza e que se destinam, na sua maioria, ao comércio internacional são:

- Narcissus asturiensis

- Narcissus bulbocodium

- Narcissus ciclamineus

- Narcissus juncifolius

- Narcissus rupicola

- Narcissus scaberulus

- Narcissus triandrus

- Urginea maritima

Em Outubro de 1991 foi dado a conhecer um documento de trabalho (Carvalho e Lopes, 1991), onde foi apresentada uma lista de plantas ameaçadas pelo comércio e exploração. Deste documento fazem parte as espécies indicadas anteriormente, bem como o Narcissus confusus pugsley, também colhido em Portugal e, sobre estes, refere: "In the Narcissus genera the species selected amoung all the species occurring in Portugal, as threatened by explotation and trade are know to be exported as bulbs to Netherland" (Carvalho e Lopes, 1991: 5).

$\mathrm{O}$ relatório intitulado Investigation in to the trade status of wild populations of Narcissus species in Portugal (Serviço Nacional de Parques, Reservas e Conservação da Natureza, 1992: 6), sublinha o seguinte: "... ao nível local os registos das colheitas para este tipo de bolbos não estão, de forma geral, disponíveis e provavelmente não foram compilados para a maior parte das espécies. A colheita pode ser feita de forma ilícita, em áreas protegidas para conservação da natureza (como é o caso português para algumas espécies de Narcisos) ou em terrenos privados. ... As empresas não fornecem informações da quantidade de bolbos obtida através destes meios, por motivos comerciais, e os importadores afirmam desconhecer a fonte do material vegetal nos países exportadores. Sem a informação acerca do estatuto das espécies na natureza e sem os níveis de colheita é difícil avaliar o impacto desta actividade." Este mesmo relatório acrescenta que se acredita que em 1987 foram exportados 519000 bolbos de Portugal e que todo o material vegetal se dirige à Holanda.

Acontece que em 1991 a Convenção relativa à Conservação da Vida Selvagem e do Meio Natural da Europa fez aprovar legislação que viria a traduzir-se em regulamentação interna, para os diferentes países pertencentes à União Europeia, impeditiva da colheita e pilhagem de bolbos selvagens. Por outro lado, as fontes estatísticas disponíveis, ao nível do Comércio Externo declarado, apenas incidem sobre o código de nomenclatura 06012030 que se 
refere, de forma agregada, a orquídeas, jacintos, tulipas e narcisos. Ora, de facto, com este nível de agregação pouco podemos saber sobre o Comercio Externo de bolbos de Narcisos, que é na sua maioria intracomunitário. Se acrescentarmos a este quadro a completa inexistência de estatísticas disponíveis, sobre o comércio interno deste tipo de produtos, percebemos a pertinência deste estudo no âmbitó do projecto de Valorização da Flora Espontânea da Serra da Estrela. Assim sendo, o estudo que realizámos procurou, antes de mais, contribuir para uma aproximação ao mercado interno ao nível dos circuitos e formas de comercialização, lógica do negócio, margens, preços e quantidades transaccionadas.

Trata-se, por isso, de um estudo de mercado de natureza exploratória com o objectivo central de aumentar o nível de conhecimentos gerais sobre a(s) forma(s) de comercialização/consumo dos bolbos de narcisos. A este nível, tornam-se centrais indicações sobre: perfil do consumo, embalagem (forma, comunicação, tamanho, calibre), preço, distribuição, estimativa sobre as quantidades envolvidas no mercado nacional, etc. Esta informação reverte da maior importância, para que possam ser atingidos alguns dos objectivos propostos neste projecto de Valorização da Flora Espontânea da Serra da Estrela e que passamos a referir:

a) Garantir a defesa das espécies no seu habitat natural, através do abastecimento alternativo do mercado com bolbos cultivados;

b) Garantir a perenidade das trocas através da satisfação da procura actual e futura, interessando os agricultores locais no processo produtivo - a engorda de bolbos

c) Garantir a genuinidade e boas características fitossanitárias das plantas fornecidas.

Estes objectivos integram uma das recomendações, feita no estudo anteriormente referido Investigation in to the trade status of wild populations of Narcissus species in Portugal (1992: 26), que aponta no sentido de ser "fundamental que seja encorajado o desenvolvimento de projectos de propagação de Narcisos, que integrem a população local proporcionando-lhe uma fonte de rendimento suplementar que substitua o rendimento auferido com a colheita directa de bolbos na natureza".

Tendo em conta estes objectivos no presente artigo apresentamos, na primeira parte, uma caracterização do estudo e a metodologia seguida para a efectiyação do mesmo. Segue-se a análise efectuada ao mercado interno, com apresentação de alguns resultados dos questionários aplicados ao retalho, através dos quais nos foi possível identificar os mais importantes "concentradores" de negócio a montante do mesmo. A estes últimos foram 
efectuadas entrevistas semi-directivas, em profundidade, que, conjuntamente com a restante informação recolhida ao longo deste trabalho, viriam a disponibilizar-nos os elementos necessários à definição das possíveis estratégias a implementar.

Por último, são tiradas algumas conclusões que se consubstanciam noutras tantas recomendações bem como em estratégias indicativas que podem/devem ser utilizadas

\section{CARACTERIZAÇÃO DO ESTUDO / METODOLOGIA}

A especificidade do produto ${ }^{3}$ em causa, aliada à quase total falta de elementos estatísticos disponíveis sobre o sector de comercialização de produtos florícolas, em geral, e de bolbos, em particular, constituiu um sério obstáculo à definição das melhores estratégias para a realização do estudo em apreço. De acordo com os dados do Comércio Externo - Entradas e Saídas, publicados pelo Instituto Nacional de Estatística, podemos verificar, para o código de nomenclatura 06012030 englobando orquídeas, jacintos, tulipas e narcisos, que os dados apresentados não reflectem, com o mínimo de rigor, o volume de negócios associado a este tipo de produtos. No quadro seguinte apresentamos os valores, para os últimos 5 anos, de importações e exportações de bolbos do código referido.

\section{Quadro n' 1}

IMPORTAÇÕES E EXPORTAÇÕES DE BOLBOS DE ORQUÍDEAS, JACINTOS, TULIPAS E NARCISOS DESDE 1995 ATÉ AO PRIMEIRO SEMESTRE DE 1999

\begin{tabular}{|c|r|r|r|r|r|r|r|r|r|r|}
\cline { 2 - 11 } \multicolumn{1}{c|}{} & \multicolumn{2}{c|}{1995} & \multicolumn{2}{c|}{1996} & \multicolumn{2}{c|}{1997} & \multicolumn{2}{c|}{1998} & \multicolumn{1}{c|}{1999 Jan./Junh. } \\
\cline { 2 - 11 } & $\begin{array}{c}\text { Massa } \\
(\mathrm{Kg})\end{array}$ & Contos & $\begin{array}{c}\text { Massa } \\
(\mathrm{Kg})\end{array}$ & Contos & $\begin{array}{c}\text { Massa } \\
(\mathrm{Kg})\end{array}$ & Contos & $\begin{array}{c}\text { Massa } \\
(\mathrm{Kg})\end{array}$ & Contos & $\begin{array}{c}\text { Massa } \\
(\mathrm{Kg})\end{array}$ & Contos \\
\hline Importaçбes & 8100 & 10053 & 4700 & 6319 & 6300 & 7026 & 8900 & 17094 & 49000 & 6196 \\
\hline Exportaçбes & 200 & 661 & 200 & 781 & 0 & 0 & 0 & 0 & 0 & 0 \\
\hline
\end{tabular}

Fonte: $\mathbb{N E E}$, dados do comércio externo, 1995 a 1999.

Como podemos verificar, os valores apresentados são manifestamente modestos, o que, desde logo, nos deixou apreensivos face às expectativas depositadas neste projecto. Todavia, os dados colhidos no terreno, como veremos, viriam a revelar-nos que, deste negócio, pelas estatísticas apenas passa uma parte meramente simbólica. 
Estudo do mercado de bolbos de narcisos: aproximação ao mercado nacional

Utilizando uma aritmética simples, admitindo que cada bolbo dos diferentes tipos poderá pesar, em média, entre 30 a 40 gramas, podemos apreciar, no quadro seguinte, o número de unidades de bolbos importados nos diferentes anos.

Quadro $n^{\circ} 2$

ESTIMATIVA DO NÚMERO DE BOLBOS IMPORTADOS

\begin{tabular}{|c|c|c|c|c|c|}
\cline { 2 - 6 } \multicolumn{1}{c|}{} & 1995 & 1996 & 1997 & 1998 & 1999 Jan./Junh. \\
\hline Peso do bolbo & $\mathrm{n}^{\circ}$. de bolbos & $\mathrm{n}^{0}$. de bolbos & $\mathrm{n}^{\circ}$. de bolbos & $\mathrm{n}$ ․ de bolbos & $\mathrm{n}$ \%. de bolbos \\
\hline $30 \mathrm{gr}$ & 270000 & 156667 & 210000 & 296667 & 1633333 \\
\hline $40 \mathrm{gr}$ & 202500 & 117500 & 157500 & 222500 & 1225000 \\
\hline
\end{tabular}

Verificamos que, em 1995, ter-se-iam importado entre 202500 a 270000 bolbos do referido código de nomenclatura, em 1996 as importações situar-se-iam entre os 117500 e os 156667 , em 1997 entre os 157500 e os 210000 , em 1998 entre os 222500 e os 296667 e, por último, no primeiro semestre de 1999 as importações situar-se-iam entre o 1,225 000 e 1,633 333 bolbos. Este salto, no primeiro semestre de 1999 , seria interessante e sustentado se o valor dessas importações em contos acompanhasse o valor em quantidades, o que, de facto, não se verifica. Se verificarmos, no quadro anterior, o valor das importações no primeiro semestre de 1999 apenas ascende a 6196 contos o que se revela manifestamente pouco para a massa envolvida que é de 49000 $\mathrm{Kg}$ de bolbos.

Se conseguimos, junto do INE, recolher estes dados sobre o comércio externo, desde logo elementos do INE nos "tranquilizaram", dizendo que sobre o mercado nacional não existem quaisquer tipo de estatísticas disponíveis.

Esta falta de elementos sobre o mercado em estudo, aliada às dificuldades decorrentes da atomização deste sector, fez com que apenas fosse possível manter o ânimo para a realização deste trabalho graças à persistência da equipa envolvida e à importância do mesmo para a prossecução do projecto de proteç̧ão da flora da Serra da Estrela. Estas dificuldades obrigaram-nos a "tatear" o caminho a trilhar, tendo em vista a recolha das informações pretendidas.

Foi assim que, numa primeira fase, entrevistámos algumas centrais de compra ligadas à distribuição, ao nível das grandes superfícies. Sobre estas entrevistas não apresentamos, neste artigo, quaisquer outros elementos, para não sobrecarregarmos a extensão do mesmo. Depois de analisadas as entrevistas, concluímos que seria necessário auscultar directamente o retalho, 
por um método de amostragem, tendo em vista o apuramento, a montante deste, das organizações responsáveis pelo "grosso" do armazenamento e distribuição de bolbos de narcisos. Propusemo-nos, então, utilizar um processo amostral com algumas características do processo amostral "bola de neve"4.

Para esta segunda fase, na ausência de outras listagens categorizadas que pudéssemos utilizar com mais proveito, servimo-nos da lista das páginas amarelas, de onde foram seleccionadas de forma aleatória as empresas que viriam a constituir a nossa base de sondagem.

Partindo desta base de sondagem fizemos o levantamento de todas as empresas que englobassem na descrição da sua actividade pelo menos uma das seguintes designações, ou raiz de designação, que denominaremos de keywords: semente, viveir, jardi, horticult, floricu e florista.

No quadro seguinte apresentamos o número de empresas por keywords e a estratificação proporcional das mesmas em função do número de questionários a incluir na amostra.

Quadro no 3

ESTRATIFICAÇÃO DAS EMPRESAS SELECCIONADAS EM FUNÇÃO DAS KEYWORDS

\begin{tabular}{|l|c|c|c|}
\hline \multicolumn{1}{|c|}{ Palavra chave } & $\begin{array}{c}\text { Número de } \\
\text { Empresas }\end{array}$ & $\%$ & $\begin{array}{c}\text { Número } \\
\text { de quest. }\end{array}$ \\
\hline semente $^{\star}$ & 164 & $18,679 \%$ & 90 \\
\hline viveir $^{*}$ & 192 & $21,868 \%$ & $\mathbf{1 0 5}$ \\
\hline jardi $^{*}$ & 212 & $24,146 \%$ & $\mathbf{1 1 6}$ \\
\hline horticult $^{\star}$ & 134 & $15,262 \%$ & $\mathbf{7 4}$ \\
\hline floricu $^{*}$ & 176 & $20,046 \%$ & $\mathbf{9 7}$ \\
\hline \multicolumn{1}{|c|}{ TOTAL. } & 878 & $100,000 \%$ & $\mathbf{4 8 2}$ \\
\hline
\end{tabular}

* A seguir à keyword podem existir mais caracteres, em qualquer número, formando palavras como, por exemplo, sementes, sementeira, etc..

A distribuição das diferentes empresas pelos 18 distritos do continente encontra-se representada no quadro seguinte. 


\section{Quadro ${ }^{\circ} 4$}

DISTRIBUIÇÃO DAS EMPRESAS SELECCIONADAS POR DISTRITOS

\begin{tabular}{|l|r|r|r|r|r|r|}
\hline \multicolumn{1}{|c|}{ Distrito } & semente & viveir & jardi & horticult & floricu & Total \\
\hline Braga & 8 & 10 & 10 & 7 & 9 & $\mathbf{4 4}$ \\
\hline Coimbra & 6 & 25 & 5 & 8 & 7 & $\mathbf{5 1}$ \\
\hline Leiria & 6 & 15 & 10 & 17 & 14 & $\mathbf{6 2}$ \\
\hline (Portalegre) & 3 & 3 & 1 & 0 & 1 & 8 \\
\hline Setúbal & 18 & 9 & 21 & 5 & 24 & $\mathbf{7 7}$ \\
\hline Viseu & 6 & 7 & 2 & 1 & 3 & $\mathbf{1 9}$ \\
\hline Aveiro & 11 & 16 & 9 & 6 & 17 & $\mathbf{5 9}$ \\
\hline (Bragança) & 2 & 3 & 2 & 0 & 0 & 7 \\
\hline (Évora) & 4 & 2 & 1 & 0 & 1 & 8 \\
\hline (Guarda) & 1 & 1 & 1 & 1 & 1 & 5 \\
\hline Lisboa & 27 & 37 & 77 & 32 & 32 & $\mathbf{2 0 5}$ \\
\hline Porto & 42 & 21 & 37 & 35 & 29 & $\mathbf{1 6 4}$ \\
\hline Viana do Castelo & 2 & 6 & 0 & 3 & 10 & $\mathbf{2 1}$ \\
\hline Beja & 8 & 4 & 0 & 3 & 5 & $\mathbf{2 0}$ \\
\hline (Castelo Branco) & 2 & 1 & 1 & 0 & 0 & $\mathbf{4}$ \\
\hline Faro & 10 & 19 & 26 & 7 & 10 & $\mathbf{7 2}$ \\
\hline Santarém & 7 & 9 & 8 & 7 & 10 & $\mathbf{4 1}$ \\
\hline (Vila Real) & 1 & 4 & 1 & 2 & 3 & $\mathbf{1 1}$ \\
\hline \multicolumn{1}{|c|}{ TOTAL } & 164 & 192 & 212 & 134 & 176 & $\mathbf{8 7 8}$ \\
\hline
\end{tabular}

Face à reduzida expressão de empresas do sector apresentada em alguns distritos $^{5}$ e admitindo que essa representatividade ao nível das páginas amarelas permite indiciar, de alguma forma, a agressividade comercial do sector nesse(s) distrito(s), optámos por inquirir apenas os distritos cujo número total de empresas do sector fosse igual ou superior a 15 o que nos conduziu a eliminar 6 dos 18 distritos.

Podemos observar, de seguida, a distribuição proporcional da amostra pelos diferentes distritos seleccionados. 


\section{Quadro $n^{\circ} 5$ \\ DEFINIÇÃO DO N DE INQUÉRITOS A REALIZAR EM FUNÇÃO DOS DISTRITOS E DAS KEYWORDS}

\begin{tabular}{|c|c|c|c|c|c|c|c|c|c|c|c|c|c|c|c|c|}
\hline \multirow[b]{2}{*}{ Distritos } & \multicolumn{3}{|c|}{ semente } & \multicolumn{3}{|c|}{ viveir } & \multicolumn{3}{|c|}{ Jardi } & \multicolumn{3}{|c|}{ horticult } & \multicolumn{3}{|c|}{ floricu } & \\
\hline & & $\%$ & & $\bar{N}$ & $\%$ & $\mathrm{n} 2$ & & $\%$ & \begin{tabular}{|l|l} 
n3 \\
\end{tabular} & \begin{tabular}{|l|l|} 
N4 \\
\end{tabular} & $\%$ & $\ln 4$ & N55 & $\%$ & & \\
\hline aga & & $\%$ & & 0 & $1 \%$ & & 10 & $\%$ & & & $2 \%$ & 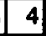 & 9 & $\%$ & & \\
\hline & & & (3) & 25 & $02 \%$ & \begin{tabular}{|l|}
14 \\
\end{tabular} & 7 & & & & & 4 & & & & \\
\hline eir & 0 & $\%$ & 3 & 15 & $31 \%$ & 8 & 10 & & 5 & 17 & 12, & 9 & 14 & & & \\
\hline & 18 & 10 & 10 & 9 & $9 \%$ & 5 & 21 & $\% \mid$ & 12 & 5 & & 3 & 24 & \begin{tabular}{|l|}
$13,64 \%$ \\
\end{tabular} & 13 & \\
\hline & & & 3 & 7 & $55 \%$ & 4 & & & & & & & 3 & & & \\
\hline & & $\%$ & 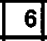 & 16 & $33 \%$ & 9 & 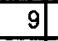 & 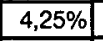 & & 4 & & 3 & 17 & $\%$ & & \\
\hline & 27 & $6 \%$ & 15 & 37 & $19,27 \%$ & \begin{tabular}{|l|}
20 \\
\end{tabular} & 77 & $36,32 \%$ & 42 & \begin{tabular}{|l|}
32 \\
\end{tabular} & $23,88 \%$ & 18 & 32 & $18,18 \%$ & 18 & 13 \\
\hline & 42 & & 23 & 21 & $10,94 \%$ & 12 & \begin{tabular}{|l|}
37 \\
\end{tabular} & & 20 & 35 & & 19 & 29 & 16, & 16 & \\
\hline & & & 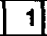 & 6 & $3 \%$ & 3 & 0 & $\%$ & 0 & 3 & & 2 & 10 & & & 12 \\
\hline & & & 7 & 4 & $8 \%$ & $\pi$ & 0 & & 4 & & & -4 & 5 & & & \\
\hline Far & & & $t$ & 19 & $0 \%$ & 10 & 26 & $12,26 \%$ & 14 & & & 4 & 10 & & & \\
\hline Santa & 7 & $7 \%$ & 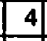 & 9 & $99 \%$ & 5 & 8 & $3,77 \%$ & 4 & 7 & $22 \%$ & 4 & 10 & $38 \%$ & 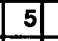 & 23 \\
\hline TOTAL & 164 & $100 \%$ & 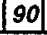 & 192 & $100 \%$ & 105 & 212 & $100 \%$ & 116 & 134 & $100 \%$ & 74 & 176 & $100 \%$ & 97 & 48 \\
\hline
\end{tabular}

Com base na distribuição apresentada na tabela anterior procedemos à selecção das empresas a inquirir de forma dirigida ${ }^{6}$. Com essa escolha produziu-se uma listagem de todas as empresas a entrevistar que não apresentamos no presente artigo por se tornar demasiadamente extensa.

Do conjunto das empresas seleccionadas, pelo processo anteriormente referido, apenas se assinalaram como obrigatórias $50 \%$ do número total de empresas a entrevistar e, para estas, um conjunto de empresas suplentes. As restantes empresas $(50 \%)$ deveriam ser escolhidas no local de realização de cada inquérito obrigatório; ou seja, por cada empresa obrigatória a ser entrevistada, constante da listagem referida, deveria ser realizado mais um inquérito a uma empresa do mesmo ramo a seleccionar na mesma rua, bairro ou localidade.

Numa primeira fase procedemos à aplicação do questionário através de um entrevistador devidamente qualificado para o efeito. Face às dificuldades sentidas na aplicação do questionário de forma personalizada, com deslocação de um entrevistador a cada estabelecimento de retalho seleccionado, optámos pela aplicação do mesmo através de uma entrevista telefónica.

Depois de concluído o inquérito ao retalho e após o tratamento desses questionários identificámos, entre outros elementos, alguns dos principais grossistas/armazenistas do sector que, na terceira fase, viríamos a entrevistar em profundidade. 
Para efeitos de tratamento e apresentação dos resultados agrupámos os 12 distritos considerados em três zonas. A primeira zona (Sul) engloba os distritos de: Santarém, Lisboa, Setúbal, Beja e Faro; a segunda (Centro), comporta os distritos de: Leiria, Coimbra, Aveiro e Viseu; por último, a terceira (Norte), onde se encontram os distritos do Porto, Viana do Castelo e Braga. Face à relativa homogeneidade dos resultados obtidos na zona Norte $\mathrm{e}$ Centro, os resultados que lhes correspondem são apresentados de forma agregada.

\section{MERCADO INTERNO / ALGUNS RESULTADOS DO ESTUDO}

As equipas que levaram a cabo o trabalho de aplicação do inquérito foram submetidas a uma sessão de formação que, para além de aspectos genéricos sobre a forma de conduzir uma entrevista, incidiu sobre o estudo em apreço, focando, em particular, aspectos relacionados com o produto (bolbos de narcisos), objectivos do estudo e entidades promotoras.

\subsection{Entrevistas ao retalho}

No que respeita ao número de fornecedores no retalho, o tratamento dos dados do inquérito revelou-nos que, neste tipo de negócio, predomina o recurso a um único fornecedor, tal como podemos observar no quadro seguinte.

\section{Quadro n' 6}

NÚMERO DE FORNECEDORES DO RETALHO POR ZONAS

\begin{tabular}{l}
\hline \multicolumn{3}{|c|}{ Zona 1 } \\
\begin{tabular}{|r|r|r|}
\hline № Fornecedores & $\mathrm{n}$ & \multicolumn{1}{c|}{$\%$} \\
\hline Não vende bolbos & 6 & $21,43 \%$ \\
\hline 1 & 14 & $50,00 \%$ \\
\hline 2 & 6 & $21,43 \%$ \\
\hline 3 & 1 & $3,57 \%$ \\
\hline$>3$ & 1 & $3,57 \%$ \\
\hline Total & 28 & $100,00 \%$ \\
\hline
\end{tabular}
\end{tabular}

\begin{tabular}{|c|c|c|}
\hline \multicolumn{3}{|c|}{$\overline{\text { Zona 2 e } 3}$} \\
\hline № Fornecedores & $n$ & $\%$ \\
\hline Não vende bolbos & 15 & $57,69 \%$ \\
\hline 1 & 6 & $23,08 \%$ \\
\hline 2 & 3 & $11,54 \%$ \\
\hline 3 & 1 & $3,85 \%$ \\
\hline$>3$ & 1 & $3,85 \%$ \\
\hline Total & 26 & $100,00 \%$ \\
\hline
\end{tabular}


A distribuição destes fornecedores por produtores e grossistas, nacionais e estrangeiros, ilustra-se no quadro $\mathrm{n}^{\circ} 7$, sendo dominante o peso dos grossistas nacionais dos quais seleccionaremos, adiante, uma listagem dos mais importantes (mais representados em termos relativos), tendo em vista a realização de uma entrevista qualificada e em profundidade.

\section{Quadro $n^{\circ} 7$}

\section{CLASSIFICAÇÃO DOS FORNECEDORES DO RETALHO POR ZONAS}

\begin{tabular}{|c|c|c|}
\hline \multicolumn{3}{|c|}{ Zona 1} \\
\hline Tipo Fornec. & $n$ & $\%$ \\
\hline Prod. nac. & 6 & $15,00 \%$ \\
\hline Prod. estr. & 8 & $20,00 \%$ \\
\hline Gros. nac. & 17 & $42,50 \%$ \\
\hline Gros. estr. & 3 & $7,50 \%$ \\
\hline Não se aplica & 6 & $15,00 \%$ \\
\hline Total & 40 & $100,00 \%$ \\
\hline
\end{tabular}

\begin{tabular}{|c|c|c|}
\hline \multicolumn{3}{|c|}{ Zona 2 e 3} \\
\hline Tipo Fornec. & $n$ & $\%$ \\
\hline Prod. Nac. & 1 & $2,86 \%$ \\
\hline Prod. Estr. & 2 & $5,71 \%$ \\
\hline Gros. Nac. & 17 & $48,57 \%$ \\
\hline Gros. Estr. & 0 & $0,00 \%$ \\
\hline Não se aplica & 15 & $42,86 \%$ \\
\hline Total & 35 & $100,00 \%$ \\
\hline
\end{tabular}

Em relação à existência de expositores, verifica-se que a maior parte do retalho utiliza unicamente a embalagem como forma de exposição dos bolbos. Todos aqueles que possuem expositores adquiriram-nos, regra geral, ao fornecedor dos bolbos.

Quadro n' 8

EXISTÊNCIA DE EXPOSITOR

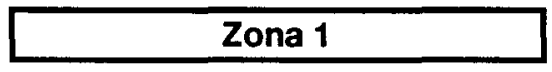

\begin{tabular}{|l|r|c|}
\hline \multicolumn{1}{|c|}{ Expositor } & $\mathbf{n}$ & $\%$ \\
\hline Sim & 5 & $12,50 \%$ \\
\hline Não & 17 & $42,50 \%$ \\
\hline Não se aplica & 6 & $15,00 \%$ \\
\hline Total & 28 & $70,00 \%$ \\
\hline
\end{tabular}

\section{Zona 2 e 3}

\begin{tabular}{|l|r|c|}
\hline \multicolumn{1}{|c|}{ Expositor } & \multicolumn{1}{c|}{$\boldsymbol{n}$} & $\%$ \\
\hline Sim & 5 & $14,29 \%$ \\
\hline Não & 6 & $17,14 \%$ \\
\hline Não se aplica & 15 & $42,86 \%$ \\
\hline Total & 26 & $74,29 \%$ \\
\hline
\end{tabular}

As vendas efectuadas pelos estabelecimentos inquiridos efectuam-se, na sua maioria, para o público em geral. Todavia, devemos referir que, na zona 1 , como podemos perceber no quadro seguinte, também têm algum significado as vendas efectuadas para "outros" onde se incluem, sobretudo, empresas de floricultura que produzem plantas de corte. 


\section{Quadro n'9}

\section{DISTRIBUIÇÃO DAS VENDAS POR TIPO DE CLIENTES}

\section{Zona 1}

\begin{tabular}{|c|c|c|}
\hline Vende para? & Peso & $\%$ \\
\hline Público geral & 121 & $43,21 \%$ \\
\hline Empres. jard. & 5 & $1,79 \%$ \\
\hline Org. públicos & 4 & $1,43 \%$ \\
\hline Outros & 90 & $32,14 \%$ \\
\hline Não se aplica & 60 & $21,43 \%$ \\
\hline Total & 280 & $100,00 \%$ \\
\hline
\end{tabular}

\section{Zona 2 e 3}

\begin{tabular}{|c|c|c|}
\hline Vende para? & Peso & $\%$ \\
\hline Público geral & 87 & $33,46 \%$ \\
\hline Empres. jard. & 16 & $6,15 \%$ \\
\hline Org. públicos & 0 & $0,00 \%$ \\
\hline Outros & 7 & $2,69 \%$ \\
\hline Não se aplica & 150 & $57,69 \%$ \\
\hline Total & 260 & $100,00 \%$ \\
\hline
\end{tabular}

Gráfico n $^{\circ} 1$

VENDAS EM PERCENTAGEM NA ZONA 1

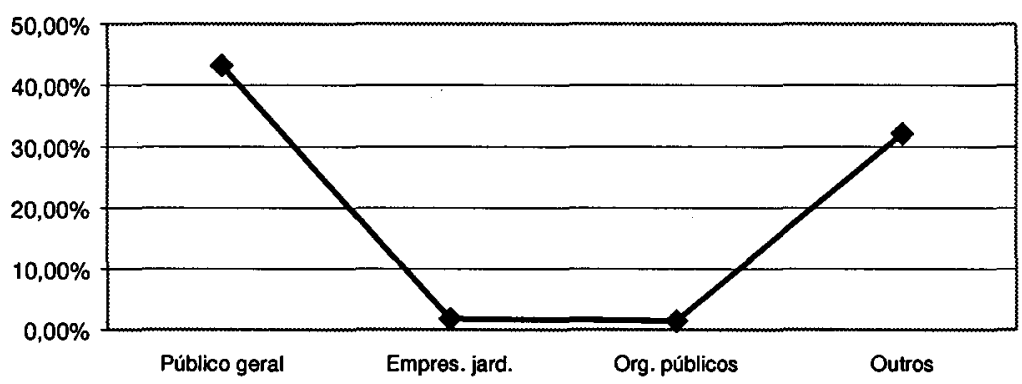

Gráfico n $^{0} 2$

VENDAS EM PERCENTAGEM NA ZONA 2

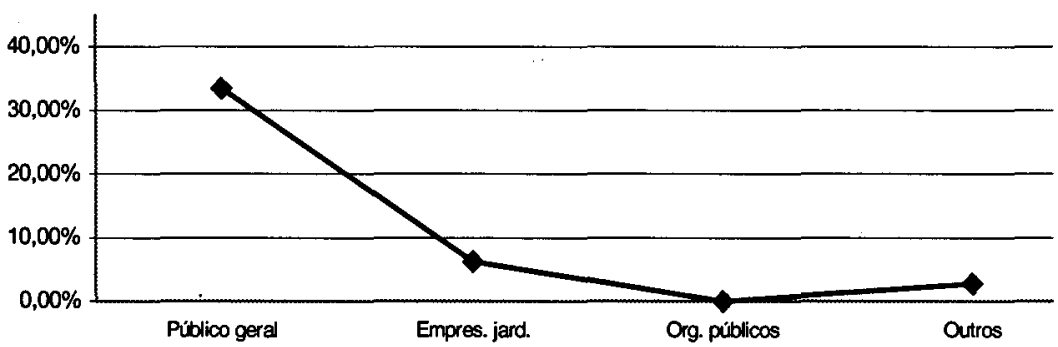




\subsection{Entrevistas aos grossistas / armazenistas}

Depois de identificados alguns dos principais "concentradores" de negócio a montante do pequeno retalho que, no presente artigo, não listamos, procedemos à entrevista dos mais representativos, utilizando, para o efeito, a entrevista semi-directiva.

De seguida, apresentamos, um exemplo da síntese dos elementos apurados num dos entrevistados.

A grande especialidade desta firma é a flor de corte. No entanto, vende alguns Bolbos: é conhecida pela qualidade garantida dos bolbos, mesmo sendo caros.

O mercado nacional de bolbos de jardim é muito concorrencial.

Os valores de compra para o ano de 1998 foram de $331000 \$ 00$, sendo apenas 16 contos de Narcisos $(4,83 \%)$. As compras/vendas concentram-se nas tulipas.

A rede de vendas é constituída por 3 colaboradores que percorrem todo o país, angariando clientes e distribuindo o produto. A entrega das encomendas é feita durante todo o mês de setembro.

As vendas de bolbos têm vindo a descer gradualmente.

Os preços praticados são os seguintes:

- Caixas com 150 bolbos: $43 \$ 00 / 54 \$ 00$ por bolbo; esta variação depende do calibre

- Saquetas de 5 bolbos: $55 \$ 00$ por bolbo (calibre 12-14) $60 \$ 00$ quando o bolbo é especial.

Normalmente as caixas que vendem são as show boxes (mix).

$\mathrm{Na} 2^{\mathrm{a}}$ fase das entrevistas tínhamos por objectivo perceber qual a sensibilidade / viabilidade de podermos utilizar os seus canais de distribuição, para colocar no mercado os narcisos confusos da Serra da Estrela.

Mostraram-se predispostos a fazerem este teste, comprando os bolbos a $30 \$ 00$ por unidade, com um calibre aproximado dos 12-14.

A embalagem preferida foi a que se apresenta de seguida, porque é aquela em que se vê melhor o tipo de flor que se está a comprar. 
Sugestões:

- Acrescentar a altura da planta

- Inserir o Código de barras. (normalmente coloca-se este código no canto inferir direito)
- Substituir pelo carimbo. 'Empurrar" para a direita, para deixar espaço para o código de barras

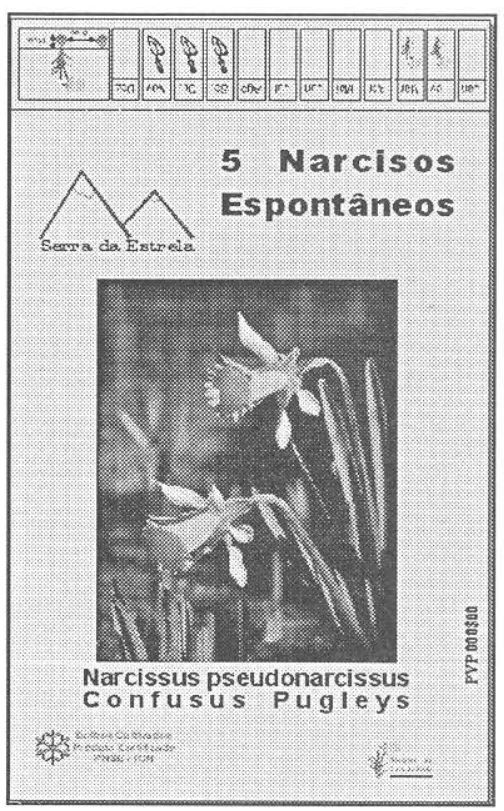

\subsection{Considerações sobre o mercado interno de bolbos de narcisus}

Antes de referirmos quaisquer elementos de natureza quantitativa, sobre o mercado de bolbos de narcisos em Portugal, gostaríamos de apresentar algumas razões que condicionaram a obtenção desses elementos.

Embora um estudo de mercado tenha, a maior parte das vezes, como objectivos fundamentais o dimensionamento do mercado em quantidades físicas e monetárias e as taxas de crescimento do mesmo, nem sempre estas variáveis se revestem da mesma importância.

Em que situações podemos considerar não serem tão pertinentes as necessidades de quantificação? De uma forma geral, em duas situações:

a) Quando sobre o produto que pretendemos comercializar não existem estatísticas que possam ser consideradas fiáveis e/ou acerca desse mesmo produto não se formou, ainda, conhecimento suficiente relacionado com aspectos tão elementares como sejam: identificação dos produtores, identificação dos canais, identificação do mix de comercialização. Assim, "Exploratory research is appropriate in situations of problem recognition and defenition." (Kinnear, 1996: 127);

b) Quando o posicionamento pretendido para o "nosso" produto não encontra no mercado nenhum concorrente directo, ou seja, o "nosso" 
produto não pode ser considerado um produto substituto e, como tal, é como se se tratasse do lançamento de um novo produto, para o qual aquilo que se torna essencial é uma reflexão sobre a melhor estratégia de comercialização, o marketing mix e a criação de cenários possiveis para a sua penetração no mercado. É neste contexto que Kinnear (1996: 127) refere: "Once the problem has been clearly defined, exploratory research can be useful in identifying alternative course of action."

Como frisámos na introdução deste artigo, um estudo de mercado, nas condições anteriormente referidas, tende a ser mais um estudo exploratório do que explicativo ou conclusivo porque, as necessidades de informação assim o impõem.

Podemos afirmar que o mercado de produção, distribuição e comercialização de bolbos de narcisos, a nível nacional, apresenta traços das duas situações anteriormente referidas. Ora, como já referimos em pontos anteriores deste artigo, foi esta situação que nos obrigou a algumas alterações de percurso, à medida que íamos conhecendo melhor o nosso objecto de estudo. Embora os elementos recolhidos nos permitam fazer algumas asserções de carácter quantitativo, que justifiquem as estratégias que apontaremos para a comercialização dos bolbos de narcisos da Serra da Estrela, consideramos que o trabalho realizado é importante, sobretudo, por aquilo que revela a nível qualitativo e de conhecimento do fenómeno em causa.

\subsubsection{Dimensão e distribuição geográfica do mercado de narcisos}

Dos elementos compilados através das entrevistas realizadas aos armazenistas, podemos afirmar que o mercado de bolbos de narcisos, referente às diferentes espécies, no ano civil de 1999, ficou compreendido entre 1000000 e 1200000 unidades. Como a produção nacional de bolbos de narcisos é insipiente ou mesmo inexistente, este valor corresponde às importações efectuadas, sobretudo da Holanda, para o nosso país.

Embora a comercialização de bolbos de narcisos se encontre pulverizada por todo o país, em estabelecimentos que vão desde as grandes superfícies aos mini-mercados, das drogarias às casas de sementes, casas de produtos hortícolas, gremios agrícolas, dos garden centers aos produtores e viveiristas com comercialização directa ao público, etc, identificámos os principais "concentradores" do negócio a montante do retalho. Estes situam-se, na sua maioria, na faixa litoral do país, com especial incidência na zona do grande Porto e grande Lisboa. 
$\mathrm{Na}$ figura seguinte apresentamos, por zonas geográficas, os principais armazenistas/grossistas do país, no negócio de bolbosas.

\author{
Figura $n^{0} 1$ \\ DISTRIBUIÇÃO GEOGRÁFICA DOS PRINCIPAIS \\ ARMAZENISTAS/GROSSISTAS DE BOLBOS DE NARCISOS
}

- Alípio Dias \& Irmão, Ida

- Casa César Santos

- Centro Agrícola e Hortícola de Gaia

- Decor Costa Verde

- Nortplantas Importação e Exportação

- Flora Lusitana

- Europlantas

- Maria Etelvina Almeida, Ida

- Cultagri

- Liscampo

- Plantimpex

- Horto do Campo Grande

- Bouga Flor

- Viveiros Vitor Lourenço

- Viveiros de São Jorge

- Sementex

- Soares \& Rebelo

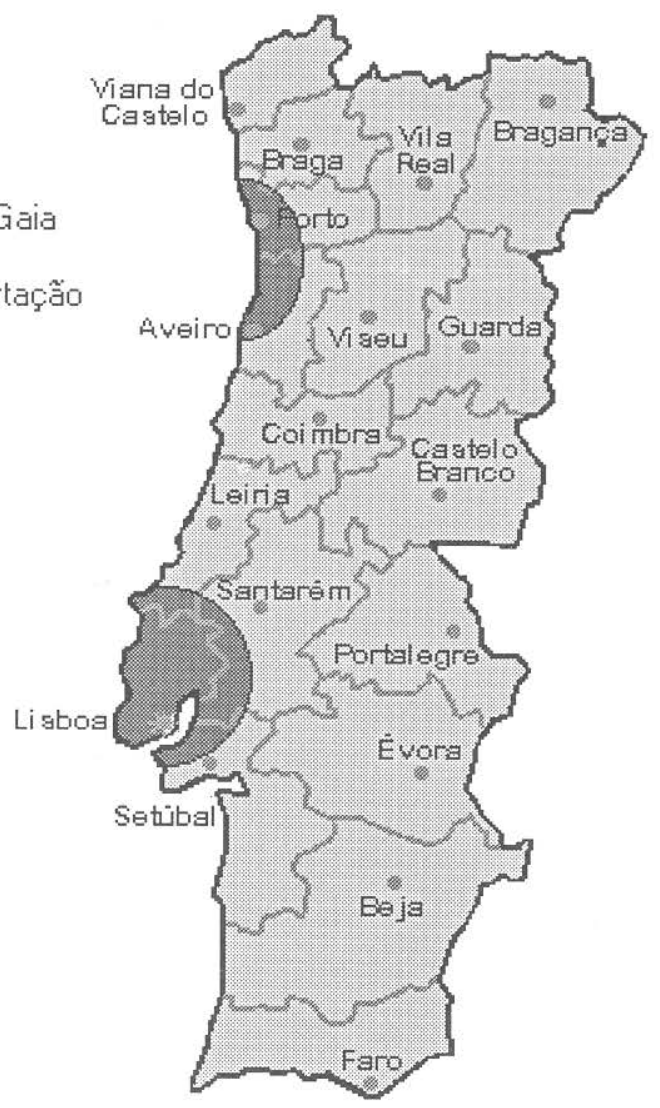




\section{ESTRATÉGIAS A DESENVOLVER / CONCLUSÕES}

Em resultado do estudo realizado pudemos apontar algumas estratégias/caminhos que podem ser seguidas, tendo em vista o sucesso da introdução desta variedade de narciso no mercado. Numa primeira fase, em que as quantidades disponíveis para a comercialização deste produto não ultrapassam cerca de 20000 bolbos (para não serem comprometidos os ritmos de duplicação), consideramos que o mercado interno é suficientemente atractivo para o seu escoamento. A comercialização de bolbos poderá assentar numa èstratégia composta por três vértices:

a) Venda de bolbos de narcisos em embalagem própria, directamente ao público, nos estabelecimentos comerciais da zona de influência da Serra da Estrela. Comercialização de caixas com 3 ou 6 bolbos de narcisos por um preço de venda ao público, respectivamente, de $110 \$ 00$ ou $210 \$ 00$, isto para um cenário de não diferenciação, face à variedade de narciso amarelo importado da Holanda. Caso contrário, num cenário de diferenciação do nosso narciso como produto nacional de elevada qualidade, o preço poderia variar entre os $250 \$ 00$ ( 3 bolbos) ou $460 \$ 00$ (6 bolbos). $O$ prémio de preço será tanto mais elevado quanto maior for a diferenciação imposta ao produto, devendo o preço de venda ao público oscilar de acordo com os cenários propostos no relatório final do estudo. A diferenciação do produto será conseguida, sobretudo, ao nível da comunicação (embalagem, cartazes, etc.) que deverá apontar para um produto certificado pelo Parque Natural da Serra da Estrela e que se destina à salvaguarda e preservação de uma espécie em extinção, preservação do meio ambiente, produto nacional de alta qualidade, etc. Por outro lado, poder-se-ia apostar na comercialização de envasados sob duas forma, a saber: envasados com floração normal para comercialização na época de floração e envasados com forçagem de floração (apontando para datas como fim do ano, Carnaval, Páscoa, etc.). 


\section{Figura $n^{\circ} 2$ \\ EMBALAGENS PARA ENVASADOS}
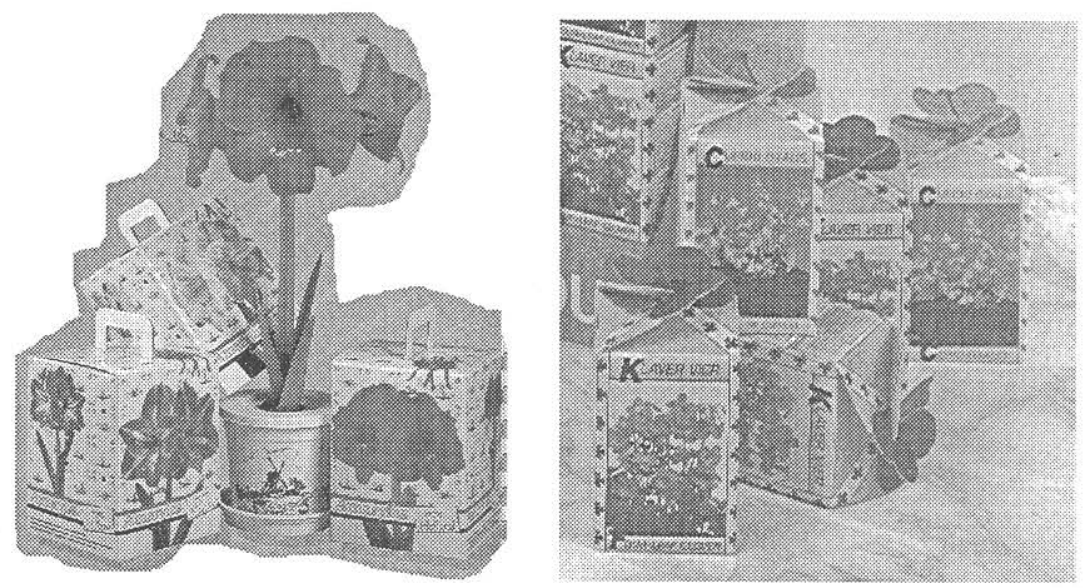

b) Integração dos bolbos de narcisos em embalagem dos tipos referidos em a), num cabaz de produtos típicos da Serra da Estrela ${ }^{7}$ (a par do mel, zimbro, queijo, etc.);

c) Difusão e divulgação desta(s) espécie(s) de narciso junto das entidades públicas e privadas responsáveis pela concepção e manutenção de jardins, parques, percursos pedestres, etc. (nomeadamente junto das autarquias locais dos concelhos abrangidos pela Serra da Estrela e circundantes, parques ecológicos, etc.).

Em simultâneo com o desenvolvimento destes três vértices parecem-nos importantes as seguintes recomendações:

- Urgência em criar as condições necessárias para a elaboração de uma política de imagem junto dos consumidores, acerca dos produtos pertencentes ao potencial endógeno da Serra da Estrela. Essa difusão poderia ser suportada, na sua maior parte, pelos organismos públicos ligados à defesa do ambiente, promoção do turismo na Serra da Estrela, etc., que poderiam integrar na sua estratégia de comunicação informações referentes a esta valência, em termos de oferta específica da Serra da Estrela.

- Apelo aos organismos oficiais, nomeadamente ao Parque Natural da Serra da Estrela, no sentido de desenvolver as diligências necessárias ao registo/protecção da comercialização das espécies de narciso selvagem originárias da Serra da Estrela. 
- Promoção de uma aproximação gradual ao mercado externo, assim que algumas condições prévias estejam satisfeitas, nomeadamente, registos de protecção à comercialização, dimensão e massa crítica da produção, etc.

- Manter/reforçar o esforço de experimentação ao nível do desenvolvimento das outras culturas de narcisos, tendo em vista, a médio/longo prazo, a diversificação da oferta de bolbos da Serra da Estrela.

- Fazer o acompanhamento técnico da acção de pré-comercialização e continuar a desenvolver o conhecimento no âmbito da comercialização deste produto, procurando aferir, entre outros:

a) perfil dos consumidores para os diferentes produtos colocados no mercado;

b) elasticidade do consumo, face ao preço e outras determinantes do produto;

c) formas de diversificação da oferta e diferenciação dos produtos já lançados no mercado;

d) canais preferenciais ao nível do mercado interno e externo.

$\mathrm{Na}$ página seguinte apresentamos um quadro, com uma síntese das medidas que julgamos importante implementar, na sequência $e$ desenvolvimento deste projecto. 


\section{Quadro n' 10 \\ SÍNTESE DAS MEDIDAS A IMPLEMENTAR}

\begin{tabular}{|c|c|c|c|}
\hline Medidas & 1999/2000 & Curto prazo & \begin{tabular}{|c|} 
Médio \\
$\mathrm{e}$ \\
longo prazo \\
\end{tabular} \\
\hline $\begin{array}{l}\text { Pré-teste de comercializacão na zona de } \\
\text { influência da Serra da Estrela } \\
\text { - Caixinha fechada com bolbo, } \\
\text { dentro de um vaso com terra ou } \\
\text { suspenso. } \\
\text { - Vaso com narciso florido. } \\
\text { - Saqueta com } 3 / 6 \text { bolbos. }\end{array}$ & $\begin{array}{l}\checkmark \\
\checkmark \\
\checkmark\end{array}$ & & \\
\hline $\begin{array}{l}\text { Plantacãa de narcisos/Difusão do conceito } \\
\text { - Parques municipais e outros em } \\
\text { Seia, Manteigas, Gouveia, ... } \\
\text { - Outros locais (PNSE, Torre, Ho- } \\
\text { téis, Turismo de habitação, Turis- } \\
\text { mo, percursos pedestres, ...) }\end{array}$ & $\checkmark$ & $\checkmark$ & $\checkmark$ \\
\hline $\begin{array}{l}\text { Institucionais } \\
\text { - Protecção à comercialização dos } \\
\text { bolbos de origem S. E. a nível } \\
\text { nacional e internacional. } \\
\text { - Estabelecimento de um } \\
\text { conceito / imagem de marca, } \\
\text { identificativa do produto típico da } \\
\text { Serra da Estrela. } \\
\text { - Criação de um cabaz de produtos } \\
\text { típicos da Serra da Estrela. }\end{array}$ & $\checkmark$ & $\begin{array}{l}\checkmark \\
\checkmark \\
\checkmark\end{array}$ & $\checkmark$ \\
\hline $\begin{array}{l}\text { Permitam a aumentar o conhecimento do } \\
\text { mercado em apreco } \\
\text { - Mercado interno } \\
\text { - Mercado externo } \\
\text { - Canais de comercialização } \\
\text { - Conservação flor de corte }\end{array}$ & $\begin{array}{l}\checkmark \\
\checkmark\end{array}$ & $\checkmark$ & \\
\hline $\begin{array}{l}\text { Que promovam a comercializacãa no } \\
\text { mercado interno, com alargamento da } \\
\text { cobertura geográfica } \\
\text { - Caixinha fechada com bolbo, } \\
\text { dentro de um vaso com terra ou } \\
\text { suspenso. } \\
\text { - Vaso com e sem forçagem de } \\
\text { floração. } \\
\text { - Saqueta com } 3 / 6 \text { bolbos. } \\
\text { - Venda da flor de corte. }\end{array}$ & & $\begin{array}{l}\checkmark \\
\checkmark \\
\checkmark\end{array}$ & $\begin{array}{l}\checkmark \\
\checkmark \\
\checkmark \\
\checkmark\end{array}$ \\
\hline
\end{tabular}


Consideramos ainda que, ao nível da divulgação destes narcisos, seria importante promover a colocação da sua flor no mercado de floristas, naquilo a que vulgarmente se chama o mercado de flor de corte. Para tal, propomos que sejam explorados alguns mercados de flores de dimensão considerável, como sejam o Mercado do Bulhão, no Porto, o Mercado de Flores que decorre semanalmente, às terças-feiras, na Maia (mercoflores), o mercado da Ribeira 24 de Julho, entre outros.

\section{NOTAS}

* O presente artigo procura reflectir algum do trabalho desenvolvido pela equipa, de natureza pluridisciplinar, que contou com a participação de:

- Eng. João F. Caldeira Cabral (Execução do Projecto)

- Prof. Doutor Alberto Martinho (Execução do Projecto)

- Mestre Paulo Castro Ribeiro (Viabilidade Económica / Estudos de Mercado)

- Dra. Madalena Santos Lima (Marketing e Análise do Produto)

Para além das pessoas referidas houve ainda a colaboração do Centro de Estudos e Sondagem de Opinião (CESOP) da Universidade Católica Portuguesa - Lisboa, Leiria e Viseu que coordenou uma parte das entrevistas realizadas ao pequeno retalho, por alunos dos referidos centros da UCP.

${ }^{1}$ Projecto de Resolução no2 do Comité Permanente sobre a Proteç̧ão das Espécies de Flora Selvagem.

${ }^{2}$ Utilizámos este conceito em vez de armazenista ou grossista na medida em que grande parte destas organizaçōes, se não a sua totalidade, pratica a par do comércio por grosso também o retalho, numa estratégia clara de "canibalizaçãa" do canal de distribuição.

${ }^{3}$ Sobre o ciclo de produção/comercialização ver Anexo I.

${ }^{4}$ Este processo amostral encontra-se consagrado na terminologia anglo-saxónica como "Snowball Sampling" e recomenda-se a sua utilização quando o atributo em estudo é de difícil localização. A metodologia a seguir, como sugere (GREEN, 1988: 328), é a seguinte: "... procedure in which initial respondents are selected randomly but where aditional respondents are then obtained from referrals or by other information provided by the initial respondents."

${ }^{5}$ Parece-nos absolutamente claro que, seguramente, existirão muito mais empresas do sector nos diferentes distritos do que aquelas que se encontram registadas nas Páginas amarelas, contudo, a distribuição e representatividade apresentada naquelas acaba, também, por reflectir as diferenças ao nível da agressividade comercial do sector nos diferentes distritos.

${ }^{6}$ Este procedimento é também referido (Kinnear, 1996: 411) como selecção por conveniência. Embora esta metodologia retire alguma possibilidade de extrapolação dos 
dados da amostra para o universo foi aquela que nos pareceu mais indicada tendo em vista a optimização das deslocações com o objectivo de realização dos inquéritos.

${ }^{7}$ Para este efeito propõe-se que se estabeleça a articulação necessária entre Parque Natural da Serra da Estrela e a(s) entidade(s) pública(s) e privada(s), com interesse na promoção desta região tendo em vista a criação de uma imagem coerente e consistente para os produtos certificados da Serra da Estrela. 


\section{ANEXO I}

CICLO DE PRODUÇÃO DOS NARCISOS

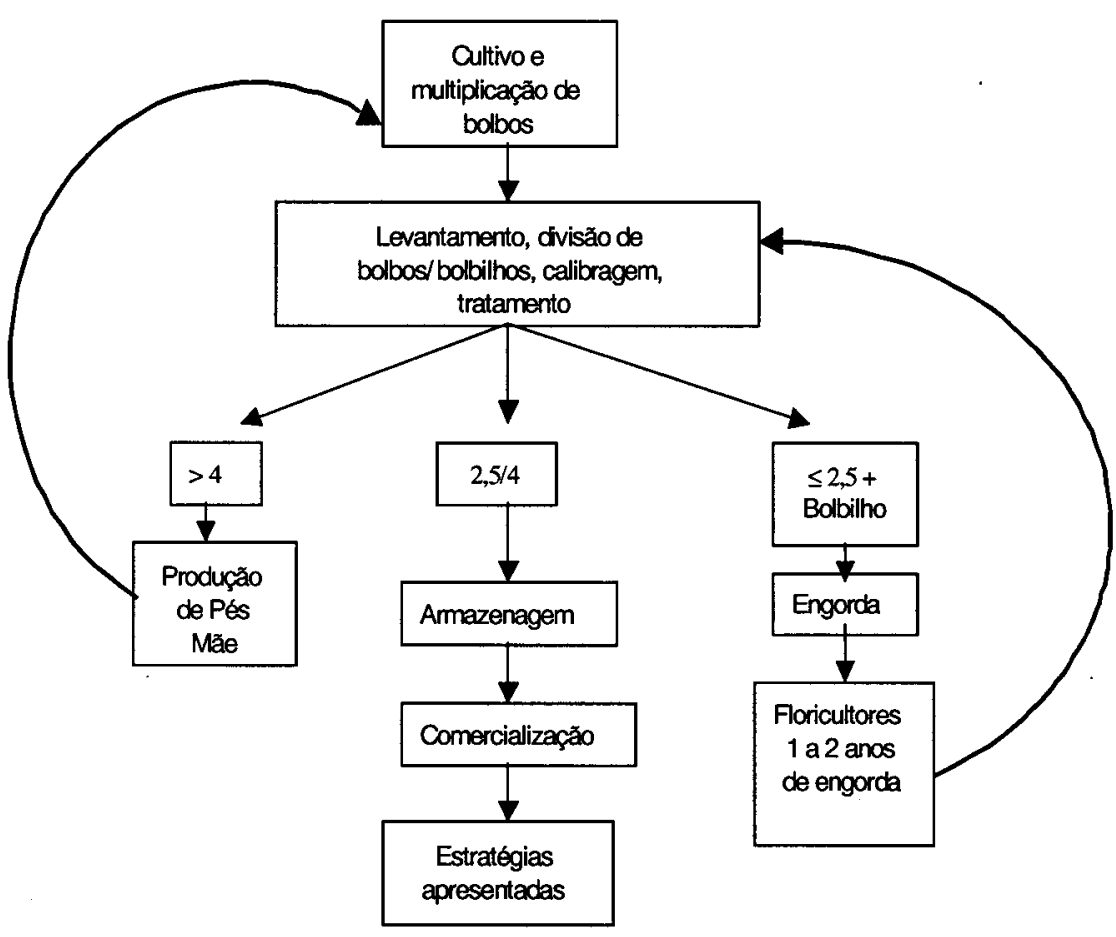




\section{BIBLIOGRAFIA}

"Convention relative a la conservation de la vie sauvage et du milieu naturel de l'europe" (1979), Project de Resolution $n^{\circ} 2$ - 1991 - sur la protection d'espèces de flore sauvages soumises à l'exploitation, Berne.

GREEN, P. e TULL, D. e ALBAUM, G. (1988), Research for Marketing Decisions, New Jersey, Prentice-Hall International.

KINNEAR, T. e TAYLOR, J. (1996), Marketing Research - An Applied Approach, Singapore, McGraw-Hill - International Editions (MS).

LOPES, Ramos e CARVALHO, L. (1991), Lista das Plantas Ameaçadas por Comércio e Exploração (policopiado).

Ministério do ambiente e dos recursos naturais, serviço nacional de parques, reservas e conservação da natureza, ( $\mathrm{s} / \mathrm{d})$, Investigation in to the trade status of wild populations of Narcissus species in Portugal. 